\title{
Pengukuran User Experience pada Aplikasi Pasbhara dengan Metode Heuristic Evaluation
}

\author{
User Experience Measurement In The Pasbhara Application Using The Heuristic \\ Evaluation Method
}

\author{
Rafika Akhsani ${ }^{1}$, Adimas Ketut N. ${ }^{2}$, M. Mujiono ${ }^{3}$, Ismanto ${ }^{4}$ \\ 1,2,3,4 Akademi Komunitas Negeri Putra Sang Fajar Blitar \\ e-mail: achsany@gmail.ac.id ${ }^{1}$,dimas@akb.ac.id², jono.kademangan@gmail.com³, \\ ism.ismanto@gmail.com ${ }^{4}$
}

\begin{abstract}
Abstrak - Kegiatan pramuka merupakan salah satu kegiatan ekstrakurikuler pada suatu sekolah. Aplikasi Phasbara adalah aplikasi berbasis android yang dibuat untuk membantu anggota pramuka dalam mendalami materi SAKA Bayangkara. Untuk mengetahui apakah aplikasi sudah sesuai dengan kebutuhan pengguna memerlukan sebuah evaluasi terhapat aplikasi itu sendiri. Penelitian ini bertujuan untuk mengevaluasi usabilitas aplikasi phasbara dan memberikan usulan perbaikan guna meningkatkan kemudahan penggunaan aplikasi Pasbhara. Pada penelitian ini menggunakan metode Heuristic Evaluation. Responden adalah anggota SAKA Bayangkara di Blitar. Data diperoleh melalui penyebaran kuesioner. Hasil penelitian menunjukkan bahwa rule-rule dalam metode heuristic evaluation yang digunakan pada penelitian yaitu Visibility of system status, Match between system and the real world, User control and freedom, Consistency and standards, Recognition rather than recall, dan Flexibility and efficiency of use mendapatkan nilai presentase persetujuan dengan rating skala setuju. Ini berarti bahwa desain antarmuka aplikasi phasbara sudah baik. Akan tetapi pada rule help and documentation juga mendapatkan persentase persetujuan dengan rating skala setuju. Ini berarti bahwa dari sisi bantuan penggunaan aplikasi masih perlu disempurnakan kembali.
\end{abstract}

Kata kunci-aplikasi phasbara; HCI ; Heuristic Evaluation; pramuka; saka bayangkara.

\begin{abstract}
Scouting activities is one of the extracurricular activities in a school. The Phasbara application is an android-based application that was created to help scout members explore the SAKA Bayangkara material. To find out whether the application is in accordance with the needs of users request an application itself. This research supports to increase the reusability of phasbara applications and to provide improvements to improve the ease of use of the Pasbhara application. In this study using the Heuristic Evaluation method. Respondents are members of SAKA Bayangkara in Blitar. Data obtained through the distribution of questionnaires. The results showed that the rules in the heuristic evaluation method used in the study were Visibility of system status, Conformity between the system and the real world, Control and freedom of users, Consistency and standards, Recognition rather than remembering, and Flexibility and efficiency of use get percentage values agreed with rating scale agree. This means that the phasbara application interface design is good. However, the rules of assistance and documentation also get approval with a scale rating agree. This means in terms of assistance that needs to be repaired.
\end{abstract}

Keywords - HCI; Heuristic Evaluation; Phasbara application; pramuka; saka bayangkara.

\section{PENDAhULUAN}

Kegiatan ekstrakurikuler merupakan kegiatan di luar jam pelajaran sekolah biasa yang dilakukan di sekolah atau di luar sekolah dengan tujuan untuk memperluas pengetahuan siswa mengenai hubungan antar mata pelajaran, menyalurkan bakat dan minat, serta melengkapi pembinaan manusia seutuhnya. Salah satu ekstrakurikuler yang ada di sekolah adalah Pramuka. Pramuka merupakan sebutan bagi anggota Gerakan Pramuka, yang meliputi; Pramuka Siaga (usia 7-10 tahun), Pramuka
Penggalang (usia 11-15 tahun), Pramuka Penegak (usia 16-20 tahun) dan Pramuka Pandega (21-25 tahun).

Untuk membantu para anggota pramuka khususnya anggota saka Bhayangkara, maka telah dibuat aplikasi berbasis android yang didalamnya memuat materi materi dasar SAKA Bhayangkara. Aplikasi ini ditujukan untuk memudahkan peserta didik dalam mempelajari materi Satuan Karya Bhayangkara. Untuk mengetahui kualitas dari aplikasi yang dibangun tentunya diperlukan tahapan evaluasi. 
Evaluasi merupakan aspek penting dalam menilai keberhasilan implementasi sebuah aplikasi. Tujuan utama evaluasi adalah untuk menilai tingkat aksebilitas dari fungsi aplikasi, menilai pengalaman interaksi pengguna dengan aplikasi serta mengidentifikasi masalah yang terjadi pada aplikasi yang dibangun. Evaluasi pengalaman interaksi pengguna memperhatikan aspek kemudahan, kegunaan dan kepuasan pengguna pada saat menggunakan sistem[1][2].

User Interface yang rumit membuat pengguna menjadi bingung dalam menggunakan aplikasi. Interface atau antarmuka berfungsi sebagai sarana untuk menjembatani antara pengguna dengan teknologi yang dibangun[3] [4][5]. Aplikasi yang sulit digunakan berarti aplikasi tersebut memiliki masalah di dalamnya. Beberapa gejala yang menunjukan sedikit kegunaan dari sebuah aplikasi diantaranya adalah lamanya waktu pelatihan bagi pemula, tingginya rata-rata kesalahan yang terjadi serta naiknya kemangkiran dari sebagian pemakai komputer. Untuk mengetahui hal tersebut, salah satu cara yang dapat digunakan adalah dengan menggunakan pendekatan usability.

Pada penelitian ini, peneliti akan melakukan evaluasi usability dengan menggunakan metode Nilsen Heuristic. Penggunaan Heuristic Evaluation lebih dikaitkan dengan pemberian umpan balik dari para pengguna aplikasi kepada para pengembang perangkat lunak. Umpan balik tersebut akan fokus terhadap sejauh mana antar muka yang kompatibel dengan kebutuhan dan preferensi pengguna dituju [6].

Sepuluh komponen Nilsen Heuristic digunakan sebagai pendekatan evaluasi usability dan sebagai dasar kuisioner yang akan diberikan kepada responden untuk mengetahui sejauh mana keberhasilan dari aplikasi yang sudah dikembangkan. Respoden diminta untuk melakukan penilaian terhadap aplikasi untuk mengetahui kepuasan pengguna terhadap aplikasi yang dikembangkan.

\section{LANDASAN TEORI}

\section{A. Evaluasi}

Evaluasi merupakan suatu proses yang dilakukan secara sistematis dan berkelanjutan dalam rangka untuk mengumpulkan, menginterpretasikan, dan menyiapkan informasi tentang suatu program sehingga dapat digunakan sebagai dasar pengambilan keputusan, menyusun kebijakan atau menyusun program selanjutnya. Dalam model interaksi Donal Norman terdapat kerangka kerja dalam interaksi yang dilakukan diantaranya (1) Penguna menetukan tujuan, (2) Merumuskan keinginan, (3) Menspesifikasikan aksi pada antarmuka, (4) Mengeksekusi aksi, (5) Mempersepsi status sistem (6) Menginteprestasikan suatu sistem, (7) Mengevaluasi status sistem yang berhubungan dengan tujuan[7].

B. User experience

Menurut ISO 9241-210 (2010), User Experience (UX) merupakan persepsi dan respon dari pengguna sebagai reaksi dari penggunaan sebuah produk, system, atau service. Hal yang dapat kita lihat dari User Experience adalah bagaimana user merasakan kesenangan dan kepuasan dalam menggunakan sebuah produk, melihat, atau memegang produk tersebut. UX tidak dapat dirancang oleh desainer tapi seorang desain dapat merancang sebuah produk yang dapat menghasilkan $\mathrm{UX}[8]$.

Untuk mengetahui User Experience dari sebuah, maka dimulai dari pengembangan sebuah produk, kemudian dilanjutkan dengan kesesuaian antara fitur produk dengan kebutuhan pengguna, apakah pengguna mudah dalam menggunakannya, serta apakah pengguna mulai senang apa yang dilihat dan dirasakan saat menggunakan aplikasi yang digunakan sehingga akhirnya dapat menciptakan User Experience yang bagus.

\section{Metode Nielsen Heurustic}

Metode Nilsen Heuristic merupakan panduan, prinsip umum, atau aturan yang digunakan untuk membuat rancangan keputusan atau digunakan untuk mengkritik suatu keputusan yang sudah diambil. Tujuan evaluasi heuristic adalah untuk memperbaiki rancangan secara efektif. Evaluator melakukan evaluasi melalui kinerja dari serangkaian tugas dengan perancangan dan dilihat kesesuaiannya dengan kriteria setiap tingkat [9]. Pengalaman Nielsen menunjukkan bahwa antara tiga dan lima evaluator cukup memadai, dengan lima biasanya menghasilkan sekitar $75 \%$ masalah kegunaan keseluruhan yang ditemukan[1]. Keluaran dari pelaksanaan metode Heuristic adalah berupa daftar heuristic yang dilanggar 
beserta saverity rating-nya [10].

Nilsen Heuristic memberikan sepuluh kriteria dalam melakukan evaluasi, diantaranya:

a. Visibilitas dari status sistem (Visibility of system status)

b. Kesesuaian antara sistem dan dunia nyata (Match between system and the real world)

c. Kendali dan kebebasan pengguna (Use Control and Freedom)

d. Standar dan konsistensi (Consistency and Standards)

e. Pencegah kesalahan (Error Prevention)

f. Bantu pengguna untuk mengenali, mendiagnosis, dan mengatasi masalah (Recognation Rather than Recall)

g. Fleksibilitas dan efesiensi (Flexibility and Efficient of Use)

h. Estetika dan desain yang minimalis (Aesthetic and Minimalist Design)

i. Pertolongan pengguna mengenal, berdialog dan memperbaiki kesalahan (Help users recognize, dialogue and recovers from errors)

j. Fitur bantuan dan dokumentasi (Help and Documentation)

\section{METODE}

Jenis dari penelitian ini adalah penelitian tindakan (action research). Action Research merupakan cara suatu kelompok atau seseorang dalam mengorganisasi suatu kondisi sehingga mereka dapat mempelajari pengalaman mereka dan membuat pengalaman tersebut dapat diakses oleh orang lain [11]. Pendekatan yang digunakan pada penelitian ini adalah dengan menggunakan pendekatan deskriptif kuantitatif. Data pada penelitian diwujudkan dalam bentuk angka dan selanjutnya dianalisis berdasarkan analisis statistik untuk melihat persepsi pengguna Pasbhara.

Penelitian ini dilakukan di Kampus Akademi Komunitas Putra Sang Fajar Blitar yang beralamat di Jalan dr. Sutomo no. 51 Telp/Fax. (0342) 844644 Kota Blitar. Subjek penelitian ini adalah anggota SAKA Bhayangkara dengan jumlah sebanyak 30 responden.

Peneliti merancang kuisioner untuk mengetahui usability aplikasi Pasbhara dengan melihat respon pengguna dalam menggunakan aplikasi tersebut. Indikator kuisioner akan dibuat sesuai dengan pandauan metode Nilsen Heuristic. Kuisioner dalam penelitian ini akan berisi pertanyaan sesuai dengan metode Nilsen Heuristic yang dipakai dengan menguraikan masing-masing kriteria dengan poin pertanyaan.

Penelitian dimulai dengan pembagian kuesioner kepada responden. Setelah responden melakukan pengisian data kuisioner, selanjutnya dilakukan kegiatan pengolahan dan analisis data. Skala pengukuran variabel dalam penelitian ini mengacu pada Skala Likert (Likert Scale) dengan menggunakan skala 1 - 4 pada setiap jawaban. Penggunaan skala 1 - 4 dilakukan untuk menghindari jawaban keraguraguan, sehingga data yang didapatkan dapat menjadi acuan perbaikan. Skala likert digunakan untuk mengukur sikap, pendapat, dan persepsi seseorang atau kelompok orang tentang fenomena sosial[12].

Dalam tahap analisis data dilakukan sesuai kode dan subdomain masing-masing domain. Teknik analisis yang dilakukan pada penelitian ini dilakukan dengan evaluasi menggunakan metode heuristic, diantaranya:

a. Melakukan perhitungan berdasarkan hasil data kuesioner yang terkumpul untuk memperoleh komponen usability yang berpengaruh terhadap usability aplikasi sesuai metode yang digunakan.

b. Melakukan pemeriksaan kuisioner untuk menentukan jumlah data yang tidak dapat dipergunakan karena salah melakukan pengisian data.

c. Menentukan frekuensi (f) dari data yang akan diolah dan dilakukan proses analisis untuk mendapatkan persentase usability.

d. Menghitung persentase jawaban responden dalam bentuk tabel tunggal melalui distribusi frekuensi dan persentase.

e. Hasil dari proses pengolahan data diatas akan menghasilkan persentase nilai usability aplikasi Pasbhara.

\section{HASIL DAN PEMBAHASAN}

A. Gambaran umum aplikasi Phasbara

Aplikasi Phasbara merupakan media pembelajaran interaktif berbasis android yang berisi tentang materi dasar Saka Bhayangkara. Pada aplikasi ini terdapat beberapa menu seperti menu POLRI, SAKA BHAYANGKARA, TIBMAS, LANTAS, PPB, PTKP. Pada saat dijalankan, aplikasi akan menampilkan splashscreen yang kemudian menampilkan menu utama yang dapat dilihat pada Gambar 1 . 


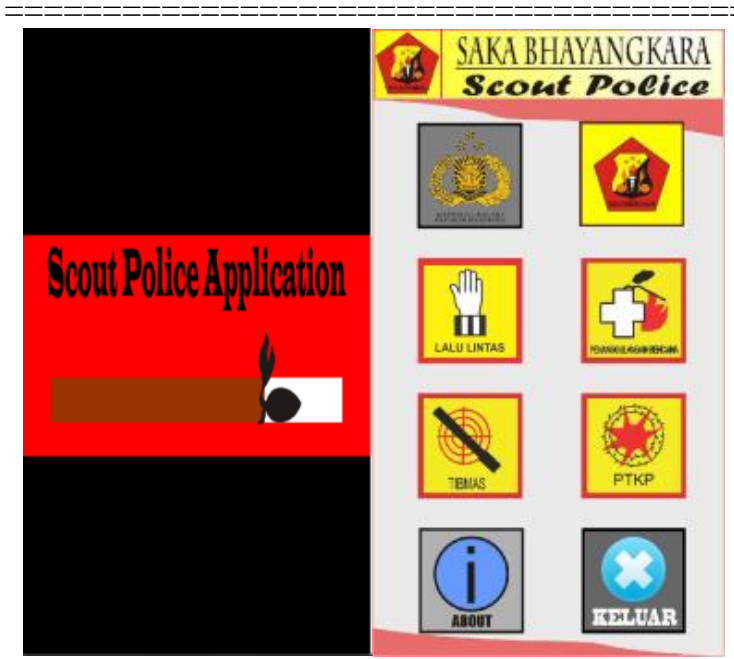

Gambar 1. Antar muka splashscreen dan menu aplikasi Phasbara

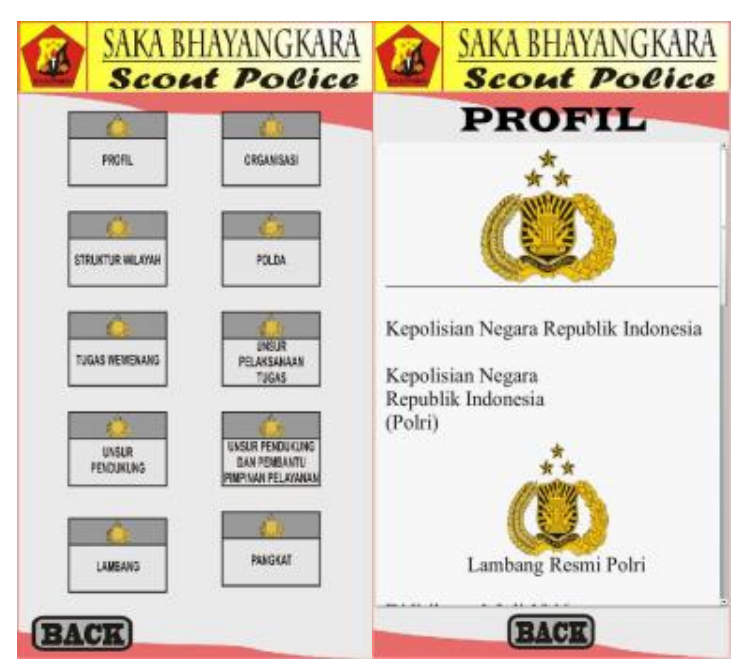

Gambar 2. Antar muka submenu dan konten aplikasi Phasbara

\section{B. Hasil dan pembahasan}

Pada proses pengolahan data, untuk melakukan perhitungan data hasil kuisioner dilakukan dengan menggunakan skor perhitungan skala likert dengan range seperti pada Tabel 1 .

Tabel 1. Range skor skala likert

\begin{tabular}{lcc}
\hline \multicolumn{1}{c}{ Uraian } & Range \\
\hline Sangat Tidak Setuju (STS) & 0 & -30 \\
\hline Tidak Setuju (TS) & $31-60$ \\
\hline Setuju (S) & $61-90$ \\
\hline Sangat Setuju (SS) & $91-120$ \\
\hline
\end{tabular}

Print ISSN: 2615-7233
Tabel 2. Hasil pengolahan data (skor ideal)

\begin{tabular}{|c|c|c|c|c|c|c|c|}
\hline \multirow{3}{*}{ NO } & \multirow{3}{*}{$\begin{array}{l}\text { KODE } \\
\text { SOAL }\end{array}$} & \multicolumn{4}{|c|}{ SKALA LIKERT } & \multirow{3}{*}{ TOTAL } & \multirow{3}{*}{$\begin{array}{c}\% \\
\text { Per } \\
\text { Setuju } \\
\text { an }\end{array}$} \\
\hline & & 1 & 2 & 3 & 4 & & \\
\hline & & STS & TS & $\mathbf{S}$ & SS & & \\
\hline 1 & VOS1 & 0 & 8 & 63 & 20 & 91 & 75.83 \\
\hline 2 & VOS2 & 0 & 20 & 48 & 16 & 84 & 70.00 \\
\hline 3 & VOS3 & 0 & 20 & 30 & 40 & 90 & 75.00 \\
\hline 4 & MBS1 & 1 & 10 & 54 & 40 & 105 & 74.17 \\
\hline 5 & UCF1 & 2 & 16 & 48 & 16 & 82 & 68.33 \\
\hline 6 & UCF2 & 0 & 16 & 45 & 28 & 89 & 74.17 \\
\hline 7 & $\mathrm{CS} 1$ & 0 & 20 & 39 & 28 & 87 & 72.50 \\
\hline 8 & RR1 & 0 & 8 & 45 & 28 & 81 & 80.83 \\
\hline 9 & RR2 & 0 & 18 & 33 & 40 & 91 & 75.83 \\
\hline 10 & RR3 & 0 & 8 & 48 & 40 & 96 & 80.00 \\
\hline 11 & FEU1 & 0 & 24 & 33 & 28 & 85 & 70.83 \\
\hline 12 & HD1 & 1 & 18 & 48 & 28 & 95 & 69.17 \\
\hline
\end{tabular}

Perhitungan data hasil kuisiner didapatkan dari skor ideal. Skor ideal merupakan skor yang digunakan untuk menghitung nilai yang menentukan rating skala dari jumlah seluruh jawaban. Untuk menghitung jumlah skor ideal dari seluruh item menggunakan cara mengalikan Nilai Skala dengan Jumlah Responden sehingga didapatkan hasil seperti pada Tabel 2.

Rule visibility of system status direpresentasikan oleh pertanyaan pertama (VOS1), kedua (VOS2), dan ketiga(VOS3). Hasil penghitungan skor skala likert dapat dilihat pada Tabel 3 sampai dengan Tabel 5.

Tabel 3. Hasil skor skala likert VOS1

\begin{tabular}{|c|c|c|c|c|}
\hline Skala & $\begin{array}{c}\text { Banyak } \\
\text { Skala }\end{array}$ & $\mathbf{x}$ & Nilai Skala & Hasil \\
\hline SS & 5 & $\mathrm{x}$ & 4 & 20 \\
\hline$S$ & 21 & $\mathrm{x}$ & 3 & 63 \\
\hline TS & 4 & $\mathrm{x}$ & 2 & 8 \\
\hline STS & 0 & $\mathrm{x}$ & 1 & 0 \\
\hline \multicolumn{4}{|c|}{ TOTAL } & 91 \\
\hline
\end{tabular}

Prosentase Jawaban

Perosentase $=(($ Frekuensi Jawaban :

75,833

Skor Ideal) x 100)

Rating scale

S

Tabel 4. Hasil skor skala likert VOS2

\begin{tabular}{ccccr}
\hline Skala & $\begin{array}{c}\text { Banyak } \\
\text { Skala }\end{array}$ & $\mathbf{x}$ & Nilai Skala & Hasil \\
\hline SS & 4 & $\mathrm{x}$ & 4 & 16 \\
\hline S & 16 & $\mathrm{x}$ & 3 & 48 \\
\hline
\end{tabular}




\begin{tabular}{|c|c|c|c|c|}
\hline Skala & $\begin{array}{c}\text { Banyak } \\
\text { Skala }\end{array}$ & $\mathbf{x}$ & Nilai Skala & Hasil \\
\hline $\mathrm{TS}$ & 10 & $\mathrm{X}$ & 2 & 20 \\
\hline STS & 0 & $\mathrm{X}$ & 1 & 0 \\
\hline \multicolumn{4}{|c|}{ TOTAL } & 84 \\
\hline
\end{tabular}

Prosentase Jawaban

Perosentase $=(($ Frekuensi Jawaban

: Skor Ideal) x 100)

Rating scale

70

S

Tabel 5. Hasil skor skala likert VOS3

\begin{tabular}{ccccr}
\hline Skala & $\begin{array}{c}\text { Banyak } \\
\text { Skala }\end{array}$ & $\mathbf{x}$ & $\begin{array}{c}\text { Nilai } \\
\text { Skala }\end{array}$ & Hasil \\
\hline SS & 10 & $\mathrm{x}$ & 4 & 40 \\
\hline S & 10 & $\mathrm{x}$ & 3 & 30 \\
\hline TS & 10 & $\mathrm{x}$ & 2 & 20 \\
\hline STS & 0 & $\mathrm{x}$ & 1 & 0 \\
\hline \multicolumn{5}{c}{ TOTAL } \\
\hline
\end{tabular}

Prosentase Jawaban

Perosentase $=(($ Frekuensi Jawaban

: Skor Ideal) x 100)

Rating scale

S

Rule Match between system and the real world direpresentasikan oleh pertanyaan keempat pada kuesioner (MBS1). Hasil penghitungan skor skala likert MBS1 pada kuesioner dapat dilihat pada Tabel 6.

Tabel 6. Hasil skor skala likert MBS1

\begin{tabular}{ccccr}
\hline Skala & $\begin{array}{c}\text { Banyak } \\
\text { Skala }\end{array}$ & $\mathbf{x}$ & $\begin{array}{c}\text { Nilai } \\
\text { Skala }\end{array}$ & Hasil \\
\hline SS & 6 & $\mathrm{x}$ & 4 & 24 \\
\hline $\mathrm{S}$ & 18 & $\mathrm{x}$ & 3 & 54 \\
\hline $\mathrm{TS}$ & 5 & $\mathrm{x}$ & 2 & 10 \\
\hline $\mathrm{STS}$ & 1 & $\mathrm{x}$ & 1 & 1 \\
\hline \multicolumn{4}{c}{ TOTAL } & 89 \\
\hline \multicolumn{4}{c}{ Prosentase Jawaban } \\
Perosentase = ((Frekuensi Jawaban \\
$\begin{array}{c}\text { : Skor Ideal) x 100) } \\
\text { Rating scale }\end{array}$ & 74,167 \\
& $\mathrm{~S}$
\end{tabular}

Rule User control and freedom direpresentasikan oleh pertanyaan kelima (UCF1) dan keenam (UCF2) pada kuesioner. Hasil penghitungan skor skala likert UCF1 dapat dilihat pada Tabel 7 dan Tabel 8 .
Print ISSN: 2615-7233
Tabel 7. Hasil skor skala likert UCF1

\begin{tabular}{ccccr}
\hline Skala & $\begin{array}{c}\text { Banyak } \\
\text { Skala }\end{array}$ & $\mathbf{x}$ & Nilai Skala & Hasil \\
\hline SS & 4 & $\mathrm{x}$ & 4 & 16 \\
\hline S & 16 & $\mathrm{x}$ & 3 & 48 \\
\hline TS & 8 & $\mathrm{x}$ & 2 & 16 \\
\hline STS & 2 & $\mathrm{x}$ & 1 & 2 \\
\hline \multicolumn{5}{c}{ TOTAL } \\
\hline
\end{tabular}

Prosentase Jawaban

Perosentase $=(($ Frekuensi Jawaban : $\quad 68,333$

Skor Ideal) x 100)

Rating scale

S

Tabel 8. Hasil skor skala likert UCF2

\begin{tabular}{|c|c|c|c|c|}
\hline Skala & $\begin{array}{c}\text { Banyak } \\
\text { Skala }\end{array}$ & $\mathbf{x}$ & Nilai Skala & Hasil \\
\hline SS & 7 & $\mathrm{x}$ & 4 & 28 \\
\hline$S$ & 15 & $\mathrm{x}$ & 3 & 45 \\
\hline TS & 8 & $\mathrm{x}$ & 2 & 16 \\
\hline STS & 0 & $\mathrm{x}$ & 1 & 0 \\
\hline \multicolumn{4}{|c|}{ TOTAL } & 89 \\
\hline
\end{tabular}

Prosentase Jawaban

Perosentase $=(($ Frekuensi Jawaban

74,167

: Skor Ideal) x 100)

Rating scale

S

Rule Consistency and standards direpresentasikan oleh pertanyaan ketujuh (CS1) pada kuesioner. Hasil dari penghitungan skor skala likert CS1 dapat dilihat pada Tabel 9

Tabel 9 . Hasil skor skala likert CS1

\begin{tabular}{|c|c|c|c|c|}
\hline Skala & $\begin{array}{c}\text { Banyak } \\
\text { Skala }\end{array}$ & $\mathbf{x}$ & $\begin{array}{l}\text { Nilai } \\
\text { Skala }\end{array}$ & Hasil \\
\hline SS & 7 & $\mathrm{x}$ & 4 & 28 \\
\hline$S$ & 13 & $\mathrm{x}$ & 3 & 39 \\
\hline TS & 10 & $\mathrm{x}$ & 2 & 20 \\
\hline STS & 0 & $\mathrm{x}$ & 1 & 0 \\
\hline \multicolumn{4}{|c|}{ TOTAL } & 87 \\
\hline
\end{tabular}

Prosentase Jawaban

Perosentase $=(($ Frekuensi Jawaban

72,5

: Skor Ideal) x 100)

Rating scale 
Rule recognition rather than recall direpresentasikan oleh pertanyaan ke-8 (RR1), ke-9 (RR2), dan ke-10 (RR3) pada kuesioner. Hasil penghitungan skor skala likert RR1 dapat dilihat pada Tabel 10 sampai dengan Tabel 12 .

Tabel 10 . Hasil skor skala likert RR1

\begin{tabular}{ccccr}
\hline Skala & $\begin{array}{c}\text { Banyak } \\
\text { Skala }\end{array}$ & $\mathbf{x}$ & $\begin{array}{c}\text { Nilai } \\
\text { Skala }\end{array}$ & Hasil \\
\hline SS & 11 & $\mathrm{x}$ & 4 & 44 \\
\hline S & 15 & $\mathrm{x}$ & 3 & 45 \\
\hline TS & 4 & $\mathrm{x}$ & 2 & 8 \\
\hline STS & 0 & $\mathrm{x}$ & 1 & 0 \\
\hline \multicolumn{5}{r}{ TOTAL } \\
\end{tabular}

Prosentase Jawaban

Perosentase $=(($ Frekuensi Jawaban

80,833

: Skor Ideal) x 100)

Rating scale

Tabel 11 . Hasil skor skala likert RR2

\begin{tabular}{ccccr}
\hline Skala & $\begin{array}{c}\text { Banyak } \\
\text { Skala }\end{array}$ & $\mathbf{x}$ & $\begin{array}{c}\text { Nilai } \\
\text { Skala }\end{array}$ & Hasil \\
\hline SS & 10 & $\mathrm{x}$ & 4 & 40 \\
\hline S & 11 & $\mathrm{x}$ & 3 & 33 \\
\hline TS & 9 & $\mathrm{x}$ & 2 & 18 \\
\hline STS & 0 & $\mathrm{x}$ & 1 & 0 \\
\hline \multicolumn{5}{r}{ TOTAL } \\
\end{tabular}

Prosentase Jawaban

Perosentase $=(($ Frekuensi Jawaban

75,833

: Skor Ideal) x 100)

Rating scale

Tabel 12 . Hasil skor skala likert RR3

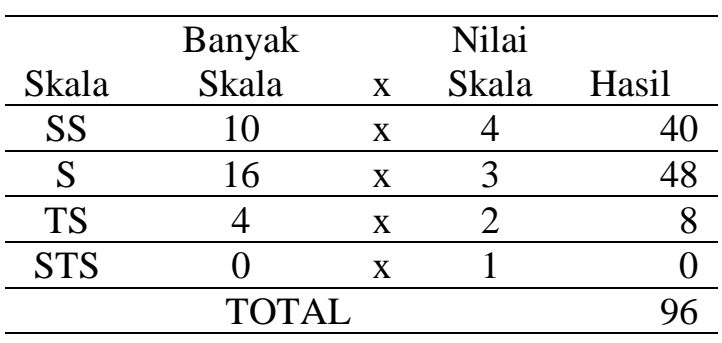

Prosentase Jawaban

Perosentase $=(($ Frekuensi

Jawaban : Skor Ideal) x 100)

Rating scale
Rule flexibility and efficiency of use direpresentasikan oleh pertanyaan ke-11 (FEU1) pada kuesioner. Hasil penghitungan skor skala likert FEU1 dapat dilihat pada Tabel 13

Tabel 13 . Hasil skor skala likert FEU1

\begin{tabular}{ccccr}
\hline Skala & $\begin{array}{c}\text { Banyak } \\
\text { Skala }\end{array}$ & $\mathbf{x}$ & $\begin{array}{c}\text { Nilai } \\
\text { Skala }\end{array}$ & Hasil \\
\hline SS & 7 & x & 4 & 28 \\
\hline S & 11 & x & 3 & 33 \\
\hline TS & 12 & x & 2 & 24 \\
\hline STS & 0 & x & 1 & 0 \\
\hline \multicolumn{4}{c}{ TOTAL } \\
Prosentase Jawaban \\
Perosentase = ((Frekuensi & 70,833 \\
Jawaban : Skor Ideal) x 100) \\
Rating scale & S
\end{tabular}

Rule help and documentation direpresentasikan oleh pertanyaan terakhir (HD1) pada kuesioner. Hasil penghitungan skor skala likert HD1 dapat dilihat pada Tabel 14.

Tabel 14. Hasil skor skala likert HD1

\begin{tabular}{ccccr}
\hline Skala & $\begin{array}{c}\text { Banyak } \\
\text { Skala }\end{array}$ & $\mathbf{x}$ & $\begin{array}{c}\text { Nilai } \\
\text { Skala }\end{array}$ & Hasil \\
\hline SS & 4 & $\mathrm{x}$ & 4 & 16 \\
\hline S & 16 & $\mathrm{x}$ & 3 & 48 \\
\hline TS & 9 & $\mathrm{x}$ & 2 & 18 \\
\hline STS & 1 & $\mathrm{x}$ & 1 & 1 \\
\hline \multicolumn{5}{c}{ TOTAL } \\
\end{tabular}

Prosentase Jawaban

Perosentase $=(($ Frekuensi Jawaban

69,167

: Skor Ideal) x 100)

Rating scale

S

\section{KESIMPULAN}

Berdasarkan hasil dan pembahasan pada bab sebelumnya, maka kesimpulan dari penelitian adalah bahwa desain antarmuka aplikasi phasbara sudah cukup baik. Hasil ini berdasarkan pada hasil skor skala likert yang menyatakan bahwa responden setuju. Variabel heuristic yang memiliki nilai usability baik diantaranya adalah Visibility of system status, Match between system and the real world, User control and freedom, Consistency and standards, Recognition rather than recall, dan help and documentation. Variabel usability 
yang perlu diperbaiki adalah Flexibility and efficiency of use karena pada saat user installasi aplikasi phasbara di smartphone, pengguna masih melakukan installasi tambahan perangkat lunak sebesar 20MB.

\section{DAFTAR PUSTAKA}

[1] J. Abouwd G. and A. Finlay, Humancomputer Interaction, 3rd ed. Inggris: Pearson Education, 2004.

[2] N. Asnawi, "Pengukuran Usability Aplikasi Google Classroom Sebagai E-learning Menggunakan USE Questionnaire (Studi Kasus: Prodi Sistem Informasi UNIPMA)," Res. Comput. Inf. Syst. Technol. Manag., vol. 1, no. 1, pp. 17-21, 2018, [Online]. Available: http://ejournal.unipma.ac.id/index.php/RESEARCH /article/view/2451/pdf.

[3] I. R. Wulandari and L. D. Farida, "Pengukuran User Experience Pada ELearning Di Lingkungan Universitas Menggunakan User Experience Questionnaire (UEQ)," J. Mantik Penusa, vol. 2, no. 2, pp. 146-151, 2018.

[4] A. Yasin and M. Yumarlin, "Evaluasi Web UJB Menggunakan Golden Rules Of User Interface Design Theo Mandel," Semin. Nas. Teknol. Inf. dan Multimed., vol. 4, no. Februari, pp. 6-7, Feb. 2016, Accessed: Apr. 26, 2020. [Online]. Available: www.janabadra.ac.id.

[5] E. P. Rozanski and A. R. Haake, Humancomputer interaction. 2017.

[6] . I. M. A. O. W., . I. K. R. A. S. T. . M. K., and . G. A. P. S. K. . M. K., "ANALISIS USER EXPERIENCE WEB BASED DIGITAL LIBRARY JURUSAN PENDIDIKAN TEKNIK INFORMATIKA UNIVERSITAS PENDIDIKAN GANESHA," Kumpul. Artik. Mhs. Pendidik. Tek. Inform., vol. 6, no. 2, p. 320, Jul. 2017, doi: 10.23887/karmapati.v6i2.11689.

[7] D. Ariyus and Sudarmawan, Interaksi Manusia dan Komputer. Yogyakarta: Andi Offset, 2007.

[8] S. Kieffer and S. Kieffer, "Representative Design in User Experience Evaluations," vol. 9, no. 2, pp. 149-172, 2017.

[9] P. Savitri and M. Ispani, "REVIEW DESAIN INTERFACE APLIKASI SOPPPOS MENGGUNAKAN EVALUASI HEURISTIK," Simetris J. Tek. Mesin, Elektro dan Ilmu Komput., vol. 6, no. 1, p. 95, Apr. 2015, doi: 10.24176/simet.v6i1.243.

[10] M. W. M. Jaspers, "A comparison of usability methods for testing interactive health technologies: Methodological aspects and empirical evidence," Int. J. Med. Inform., vol. 78, no. 5, pp. 340-353, May 2009, doi: 10.1016/j.ijmedinf.2008.10.002.

[11] M. T. Kemmis, The Action Research Planner Victoria. Deakin University, 1982.

[12] Sugiono, Metode Penelitian Pendidikan (Pendekatan Kuantitatif, Kualitatif, dan $R \& D)$. Bandung: Alfabeta, 2011. 